\title{
PENENTUAN KADMIUM MENGGUNAKAN METODE PAPER ANALYTICAL DEVICE (PAD) DENGAN TEKNIK PENCITRAAN DIGITAL DALAM SAMPEL MAKANAN
}

\author{
Zuri Rismiarti ${ }^{1)}$ \\ ${ }^{1)}$ Prodi Diploma Analisis Farmasi dan Makanan (Anafarma), Jurusan Gizi \\ Politeknik Kesehatan Kemenkes Malang \\ Malang, Indonesia \\ e-mail: zurirismiarti@gmail.com
}

\begin{abstract}
ABSTRAK
Kadmium merupakan salah satu logam berat dari sepuluh bahan kimia berbahaya dan menjadi perhatian kesehatan masyarakat. Kadmium (Cd(II)) bukan merupakan logam esensial dalam tubuh manusia maupun tumbuhan dan hewan yang berdampak kronis bagi kesehatan dan lingkungan. Berbagai metode telah banyak dikembangkan untuk mendeteksi kandungan kadmium dalam berbagai sampel. Salah satu metode yang dipelajari adalah paper analytical device berbasis kompleks Alizarin Red $S$. dengan analisis menggunakan teknik pencitraan digital. Metode ini menggunakan kertas Whatmann sebagai media sampel dan reagen pengkelat yang akan menghasilkan warna kuning sehingga dapat dianalis secara kolorimetri. Tujuan penelitian ini adalah menentukan kandungan Cd(II) dalam sampel makanan dengan metode PAD berbasis kompleks Alizarin Red S. Penelitian dilakukan di Laboratorium Kimia-Farmasi Universitas Ma Chung pada bulan Agustus-November 2017. Sampel yang digunakan adalah daun kangkung, ikan segar mujaer, lele, dan pindang tongkol dengan hasil analisis Cd(II) (mg/g) masing - masing secara berurutan adalah $0.139 ; 0.210 ; 0.3410 .409$. Hasil pengujian metode ini juga dibandingkan dengan metode standar AAS (Atomic Absorption Spectrometer).
\end{abstract}

Kata kunci: kertas, kadmium, makanan, pencitraan, digital

\section{DETERMINATION OF KADMIUM USING PAPER ANALYTICAL DEVICE (PAD) METHOD WITH DIGITAL IMAGING TECHNIQUE IN FOOD SAMPLE}

\begin{abstract}
Cadmium is one of a heavy metal from ten chemicals of major public health concern. Cadmium is not essential metal in the human body as well as animals, plants which acquire chronic impact for heath and the environment. Many methods have been developed to detect trace $\mathrm{Cd}$ (II) in various sample. One of that method is paper analytical device based on Alizarin Red S complex using digital color image analysis. The method used Whatmann Paper as a media sample and chelating reagents which produce yellow color complex that can analyze colorimetry. The purpose of this research of determination Cd(II) in food samples using PAD based on Alizarin Red S complex. The experiment was conducted at the Chemical-Pharmaceutical Laboratory, Ma Chung University in August-November 2017. Samples are convolvulus leaves, fresh fish like mujaer, catfish, cobs with the results of $\mathrm{Cd}(\mathrm{II})(\mathrm{mg} / \mathrm{g})$ of each sample of $0.139 ; 0.210 ; 0.3410 .409$ respectively. The result of the proposed methods is compared with standard method of AAS (atomic absorption spectrometer).
\end{abstract}

Keywords : paper, cadmium, food, digital, color

\section{PENDAHULUAN}

Buangan limbah industri yang mengandung logam berat dengan toksisitas yang tinggi dan kemampuan biota laut untuk menimbun logam tersebut langsung terakumulasi secara fisik dan kimia

kemudian mengendap di dasar perairan. Salah satu logam pencemar tersebut adalah kadmium. Fenomenal kasus keracunan kadmium terjadi di Jepang karena proses penambangan yang memberikan efek kesehatan bagi penduduk sekitar area pertambangan. Penduduk sekitar terkena 
penyakit Itai-itai Disease setelah mengkonsumsi air sungai Jinzu serta memakan beras yang diirigasi oleh sungai tersebut. Kadmium dapat terakumulasi dalam di tubuh manusia serta baru dapat keluar dari dalam tubuh, tatapi dengan waktu tunggu berkisar antara 20-30 tahun lamanya. Efek dalam tubuh pun beragam, mulai dari hipertensi sampai kanker karena jika enzim bergabung dengan logam berat terutama enzim yang mengandung sulfur maka enzim tersebut berubah sifat menjadi penyebab kanker. Selain pada manusia, kadmium juga memberikan efek kematian pada ikan yang media hidupnya telah terpapar kadmium pada rentang konsentrasi 1,092-1,104 ppm kadmium. Sedangkan jika tumbuhan yang terpapar logam $\mathrm{Cd}$, akan mengakibatkan terhambatnya peristiwa penyerapan partikulat-partikulat yang sangat dibutuhkan oleh klorofil sebagai zat hijau daun. Jika ikan dan tumbuhan (daun) yang telah terpapar kadmium dikonsumsi oleh manusia maka dapat memberikan dampak yang sangat kronis bagi kesehatan karena menyebabkan kerusakan-kerusakan pada sistem fisiologi tubuh (Prayitno, 2007; Istarani dan Pandebesie, 2014).

Analisis kadmum (Cd) menggunakan instrumentasi seperti AAS (Atomic Absorption Spectrometry), ICP-AES (Inductively Coupled Plasm-Atomic Emission Spectrometry), ICP-MS (Inductively Coupled Plasma-Mass Spectrometry), FAAS (Flame Atomic Absorption Spectrometry) telah dikembangkan secara luas (Cesur and Bati, 2002; Rawat et al., 2012). Ong (2014) melaporkan penentuan logam kadmium dalam sampel olahan makanan (daging, ikan) dengan menggunakan Graphite Furnace Atomic Absorption Spectroscopy (GFAS).

Marzo, et al., (2013) melaporkan pembuatan kertas sensitif dan integrasi berbasis sistem imunosistem sebagai sensor $\mathrm{Cd}$ (II) dalam lateral flow format serta telah berhasil diaplikasikan dalam sampel air minum. Selain itu, teknik PAD (Paper Analytical Device) juga telah dikembangkan untuk monitoring logam tembaga $(\mathrm{Cu})$ dengan membuat kertas Whatmann No.1 sebagai device yang bersifat sensitif dan selektif berbasis sensor kolorimeter yang diteteskan oleh sampel dan reagen (Chaiyo, et al., 2015).

Metode PAD telah dikembangkan dalam penentuan kadmium dengan menggunakan reagen pengompleks reagen alizarin red $s$ sehingga membentuk larutan warna kuning di kertas Wahtmann (Rismiarti dan Indrawati, 2017). Karakterisasi hasil penelitian menunjukkan konsentrasi optimum dari Alizarin Red $\mathrm{S}$ dan $\mathrm{H}_{2} \mathrm{SO} 4$ masing- masing sebesar $750 \mathrm{ppm}$ dan 0,05 $\mathrm{M}$ dengan waktu pengukuran sebesar 10 menit. Kompleks $\mathrm{Cd}$ dengan reagen pengompleks Alizarin Red S ditunjukkan pada Gambar 1 (Rawat, et al., 2012).

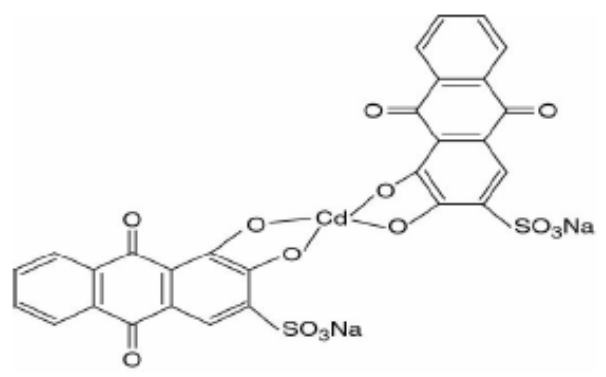

Gambar 1. Kompleks Cd-Alizarin Red S (Rawat, et al., 2012)

Tahap selanjutnya dari metode tersebut adalah analisis secara kolorimetri dengan teknik pencitraan digital Teknik ini menggunakan software image J 1.48 untuk menghasilkan intensitas pada masing-masing warna komplementer, merah, hijau, biru kemudian diolah dalam penentuan absorbansi dengan menggunakan persamaan Lambert-Beer. Program ini dikenal dengan teknik pencitraan digital dan telah berhasil digunakan untuk menganalisis sampel air sumur dalam penentuan kadar besi (III) (Rusmawan, et al., 2011).

Metode PAD-Kadmium dengan reagen pengompleks Alizarin Red S belum diaplikasikan ke dalam sampel nyata untuk deteksi logam kadmium pada sampel makanan. Oleh sebab itu, penelitian ini bertujuan untuk mendeteksi kadmium dalam sampel makanan dengan metode PAD berbasis kompleks Cd(II)-Alizarin Red $S$ dengan analisis menggunakan teknik pencitraan digital.

Tujuan penelitian ini adalah menentukan kandungan Cd(II) dalam sampel makanan dengan metode PAD berbasis kompleks Alizarin Red S. Penelitian 
dilakukan di Laboratorium Kimia-Farmasi Universitas Ma Chung pada bulan AgustusNovember 2017. Penelitian ini dengan prinsip kolorimetri berbasis kompleks berwarna kuning kehijauan pada $\mathrm{pH}$ asam. Sampel yang digunakan adalah makanan berupa ikan segar pindang tongkol, lele, mujaer dan daun kangkung. Kandungan kadmum dalam sampel makanan diperoleh dari hasil interpolasi dari kurva standar kadmium dengan metode PAD. Preparasi sampel makanan tersebut dengan destruksi basah dan microwave yang kemudian hasil destruksi tersebut digunakan sebagai sampel cair dan dianalisis kandungan kadmium dengan metode PAD.

\section{METODE PENELITIAN}

\section{Alat dan Bahan}

Alat - alat yang digunakan dalam penelitian ini adalah kertas Whatman No.42, neraca analitik, pemanas listrik, pipa kapiler, AAS tipe 240, microwave model MDS 6.

Bahan yang digunakan dalam penelitian ini mempunyai sifat pro analisis antara lain $\mathrm{CdSO} 4$ (E-Merck), $\mathrm{H}_{2} \mathrm{SO}_{4}$ concentrated (E-Merck), Alizarin Red S (EMerck) akuades, cranyon wax, ikan segar pindang tongkol, lele, mujaer, daun kangkung

\section{Pembuatan Paper Analytical Devices (PAD) untuk Kadmium \\ Pembuatan \\ PAD-Kadmium} mengacu pada penelitian Rismiarti dan Indrawati, (2017)Paper-based devices didisain pada kertas Whatman No. 42 yang sudah dipola berbentuk persegi panjang dengan ukuran $5 \times 2 \mathrm{~cm}$. Pembuatan batas hidrofobik menggunakan cranyon wax pada sisi lingkaran. Selanjutnya kertas saring dipanaskan di hot plate pada temperatur 120 ${ }^{\circ} \mathrm{C}$ selama 5 menit sehingga malam bisa berpenetrasi sehingga membentuk batas hidrofobik.

Pembuatan Kurva Kalibrasi Cd(II) Dengan Metode PAD Berbasis Kompleks Alizarin Red S Menggunakan Teknik Pencitraan Digital

Dengan menggunakan 5 buah pola PAD yang telah dipreparasi, selanjutnya masing-masing pola kertas saring tersebut ditetesi menggunakan pipa kapiler dengan $\mathrm{Cd}$ (II) 0,$1 ; 0,3 ; 0,5 ; 0,7$ dan 1 ppm; kemudian ditetesi dengan Alizarin Red $S 750$ ppm dan asam sulfat $0,05 \mathrm{M}$ sehingga terjadi pergerakan sampel melalui kapiler kertas. Kertas saring yang mengandung Alizarin Red S dan Cd(II) menunjukkan warna kuning. Warna kuning yang terbentuk masing - masing diphoto dengn hp android, kemudian hasilnya diproses menggunakan Image J software 1.48. Kemudian nilai intensitas yang muncul dirubah menjadi nilai absorbansi, menggunakan Hukum LambertBeer pada persamaan 1. Untuk setiap warna pada kertas ditentukan nilai RGB (Red, Green Blue) (Kohl, et al., 2006).

$$
A=-\log \left(\frac{I}{I_{0}}\right)
$$

Keterangan: A adalah absorbansi; I adalah intensitas sampel atau kontrol dan Io adalah intensitas pelarut dengan nilai 255 .

Dari nilai absorbansi pada masingmasing konsentrasi $\mathrm{Cd}(\mathrm{II})$ kemudian diplotkan ke dalam kurva kalibrasi dengan absis adalah konsentrasi $\mathrm{Cd}(\mathrm{II})$ (ppm) dan ordinat adalah absorbansi. Masing - masing warna komplementer RGB dibuat kurva kalibrasi. Dari hasil kurva dari masingmasing warna komplementer RGB dapat ditentukan jenis warna komplementer yang dapat dijadikan acuan dalam menentukan persamaan regresi.

\section{Preparasi Sampel Makanan}

Preparasi sampel makanan dengan cara menimbang bahan makanan (ikan tongkol pindang, lele, dan mujaer masingmasing sebanyak $0,5 \mathrm{~g}$ sedangkan kangkung sebanyak $2 \mathrm{~g}$ kemudian didestruksi basah dengan penambahan asam nitrat pekat $\left(\mathrm{HNO}_{3}\right) 65 \%$ dan $2 \mathrm{~mL}$ hidrogen peroksida $\left(\mathrm{H}_{2} \mathrm{O}_{2}\right)$. Selanjutnya di destruksi menggunakan microwave model MDS 6 selama 30 menit dengan pengaturan suhu sebagai berikut:

\begin{tabular}{|r|c|r|c|}
\hline Tahap & $\left.\mathbf{T} \mathbf{(}^{\mathbf{0}} \mathbf{C}\right)$ & $\mathbf{t}$ (menit) & Daya $(\mathbf{W})$ \\
\hline 1 & 130 & 10 & \multirow{2}{*}{700} \\
\cline { 1 - 3 } 2 & 150 & 0.5 & \multirow{2}{*}{700} \\
\hline 3 & 190 & 15 & \\
\hline
\end{tabular}


Kemudian didinginkan lalu disaring dengan kertas saring hingga terbentuk warna larutan jernih.

\section{Analisis Cd(II) dalam sampel makanan dengan teknik PAD}

Hasil preparasi sampel bahan makanan yang berbentuk cairan tersebut dianalisis menggunakan metode PAD yang akan diusulkan. Dengan cara menyiapkan kertas PAD yang telah dipreparasi. Kemudian hasl destruksi masing-masing sampel makanan (ikan segar pindang tongkol, lele, mujaer, dan daun kangkung) diteteskan ke dalam kertas PAD menggunkan pipa kapiler, dilanjutkan dengan penetsan dengan dengan Alizarin Red $S 750 \mathrm{ppm}$ dan asam sulfat $0,05 \mathrm{M}$ sehingga terbentuk warna kuning. Warna kuning yang dihasilkan kemudian ditentukan intensitas dengan teknik pencitraan digital. Masing-masing sampel makanan memberikan intensitas pada tiap warna komplementer red, green, blue (RGB) kemudian ditentukan absorbansinya dengan menggunakan persamaan Lambert-Beer. Hasil masing-masing absorbansi pada tiap sampel makanan di interpolasikan ke dalam kurva kalibrasi $\mathrm{Cd}(\mathrm{II})$ sehingga dapat ditentukan kandungan kadmium.

Hasil destruksi juga dilakukan analisa $\mathrm{Cd}(\mathrm{II})$ dengan menggunakan AAS pada panjang gelombang $228,8 \mathrm{~nm}$.

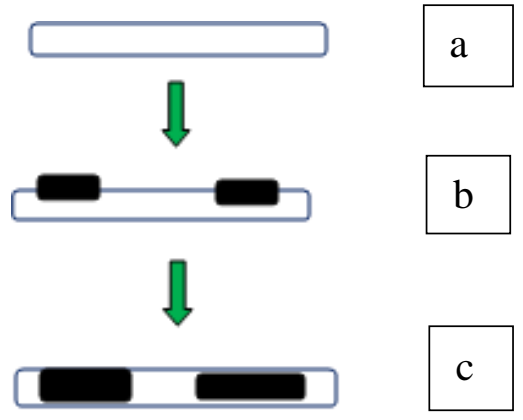

Gambar 2. Mekanisme Malam Berpenetrasi dalam Kertas (a) Bagian Permukaan Kertas Whatmann, (b) Malam meleleh dalam selolosa kertas dengan pemanasan (c) Malam berpenetrasi melewati selulosa membrane dan membentuk batas hidrofobik.

\section{HASIL DAN PEMBAHASAN}

Preparasi PAD dilakukan dengan menyiapkan kertas saring whatmann No. 41 kemudian dilapisi batas pola dengan menggunakan cranyon wax. Penggunaan malam untuk melapisi kertas yang diikuti dengan pemanasan $125{ }^{\circ} \mathrm{C}$ selama 5 menit agar malam bisa berpenetrasi sehingga membentuk batas hidrofobik sehingga membentuk batas hidrofobik seperti ditunjukkan pada Gambar 2 (Liana, et al ., 2012).

Kompleks warna kuning tersebut kemudian difoto dengan kamera hp lalu dianalisis menggunakan teknik pencitraan digital S. Teknik ini menggunakan software Image J 1.48 untuk memperoleh intensitas larutan kompleks dari masing-masing warna komplementer red green blue (R,G, B). Mekanisme untuk mendeteksi senyawa kompleks Cd(II)-Alizarin Red $S$ menggunakan teknik pencitraan digital ditunjukkan pada Gambar 3 (Busa, et al., 2016).

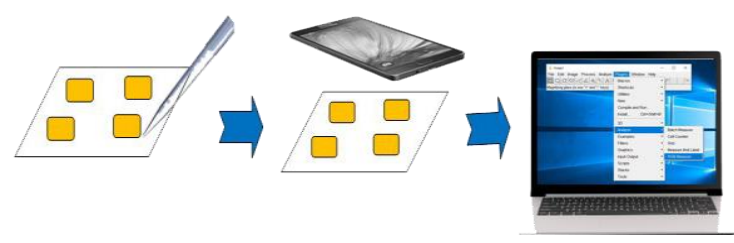

Gambar 3. Deteksi Senyawa Dengan Menggunakan Teknik Pencitraan Digital.

Dengan mengetahui intensitas dari larutan kompleks Cd(II)-Alizarin Red $S$ maka dapat ditentukan absorbansi dengan penggunakan persamaan Lambert Beer dari persamaan 1 .

\section{Pembuatan Kurva Kalibrasi Cd(II) Dengan Metode PAD}

Nilai absorbansi dan intensitas warna kompleks Cd(II)-Alizarin Red $S$ disajikan pada Tabel 1 dan 2. Dari Tabel 1 terlihat intensitas yang diperoleh dari warna komplementer Red dan Green tidak menujukan perubahan yang signifikan pada masing-masing konsentrasi $\mathrm{Cd}$ (II) sehingga absorbansi yang dihasilkan juga hampir sama di konsentrasi Cd(II) yang berbeda.

Hal ini didukung dari hasil warna kompleks kuning kehijauan yang terbentuk, 
tidak menunjukkan gradasi warna pada konsentrasi Cd(II) yang berbeda. Sebaliknya pada warna komplementer blue, diperoleh intensitas yang semakin menurun dengan meningkatnya konsentrasi Cd(II) sehingga absorbansi yang diperoleh semakin besar yang ditunjukkan dari gradasi warna kompleks yang dihasilkan pada masingmasing konsentrasi. Semakin tinggi konsentrasi $\mathrm{Cd}(\mathrm{II})$, maka warna kompleks kuning kehijauan yang terbentuk semakin pekat. Oleh sebab itu, warna komplementer blue, digunakan sebagai data acuan dalam penentuan liniearitas pengukuran.

Tabel 1. Nilai Intensitas Kompleks Cd(II)Alizarin Red $S$ Pada Berbagai Variasi Konsentrasi

\begin{tabular}{|c|c|c|c|}
\hline Cd(II) & \multicolumn{3}{|c|}{ Intensitas } \\
\hline ppm & Red & Green & Blue \\
\hline 0.1 & 162.959 & 165.657 & 115.13 \\
\hline 0.3 & 160.353 & 164.391 & 107.01 \\
\hline 0.5 & 157.041 & 158.957 & 101.02 \\
\hline 0.7 & 156.667 & 158.823 & 84.95 \\
\hline 1 & 155.84 & 156.767 & 69.40 \\
\hline
\end{tabular}

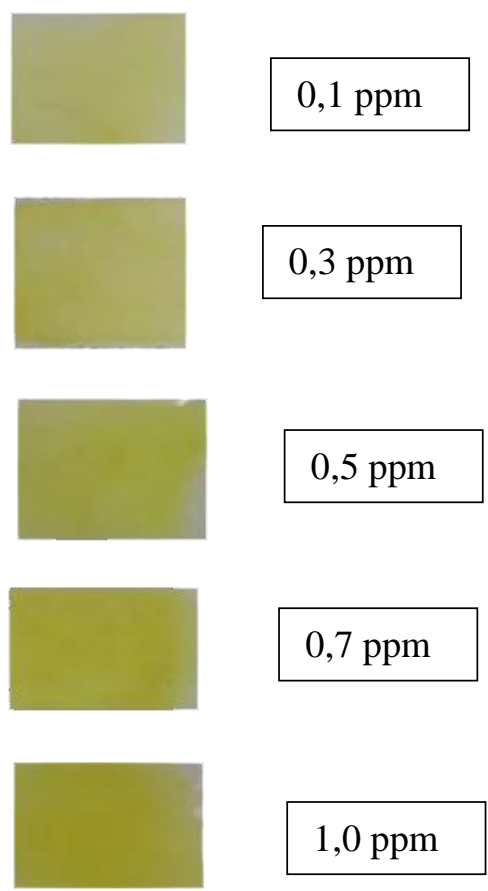

Gambar 4. Warna Kompleks Cd(II)Alizarin Red $S$ dapa Berbagai Konsentrasi $\mathrm{Cd}(\mathrm{II})$.

Dalam pembuatan kurva kalibrasi $\mathrm{Cd}$ (II) dibuat beberapa variasi konsentrasi Cd(II) kemudian diteteskan ke dalam kertas PAD yang telah dipreparasi kemudian ditambhan reagen alizarin Red $S$ sehingga membentuk kompleks berwarna kuning yang ditunjukkan pada Gambar 4.

Tabel 2. Nilai Absorbansi Kompleks Cd(II)Alizarin Red $S$ Pada Berbagai Variasi

Konsentrasi

\begin{tabular}{|c|c|c|c|}
\hline Cd(II) & \multicolumn{3}{|c|}{ Absorbansi } \\
\hline $\mathbf{p p m}$ & Red & Green & Blue \\
\hline 0.1 & 0.194 & 0.187 & 0.345 \\
\hline 0.3 & 0.201 & 0.191 & 0.377 \\
\hline 0.5 & 0.211 & 0.205 & 0.402 \\
\hline 0.7 & 0.212 & 0.206 & 0.477 \\
\hline 1 & 0.214 & 0.211 & 0.565 \\
\hline
\end{tabular}

Tabel 2 menunjukkan bahwa rentang konsentrasi liner dari metode PAD- Cd(II)alizarin red $S$ adalah 0,1 hingga 1 ppm. Absorbansi yang dihasilkan dari masingmasing konsentrasi tersebut juga telah memenuhi absorbansi dari persamaan Lamber Beer $(0,2<\mathrm{A}<0,8)$.

Pada Gambar 5 menunjukkan grafik kurva kalibrasi ditunjukkan rentang linearitas $\mathrm{Cd}$ (II) pada konsentrasi 0,1 hingga 1 ppm berdasarkan metode PAD yang diusulkan. Jika konsentrasi Cd(II) antara 0 sampai 1 ppm maka kurva linearitas yang digunakan dengan persamaan regresi linier y $=0,2483 \mathrm{x}+0,3043$ dengan $\mathrm{R}^{2}=0,9642$.

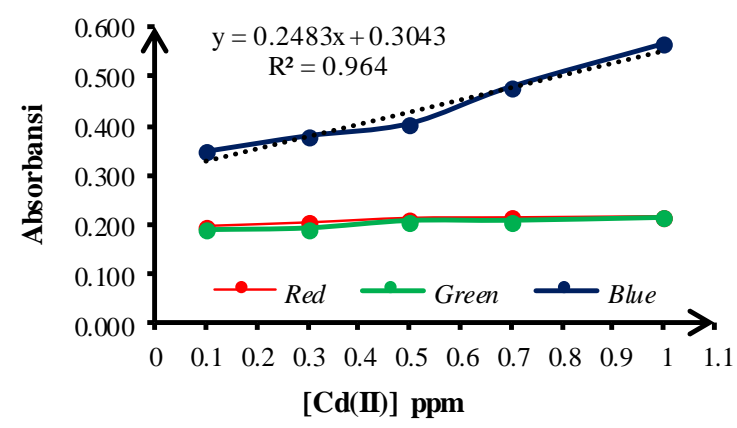

Gambar 5. Kurva Kalibrasi Cd(II) dengan Metode PAD

Mengacu pada SNI 7387:2009 menyebutkan bahwa ambang batas Cd(II) untuk ikan dan olahanya adalah $0,1 \mathrm{mg} / \mathrm{Kg}$; ikan predator misalnya cucut, tuna, marlin dll adalah $0,5 \mathrm{mg} / \mathrm{Kg}$ dan kekerangan, moluska, teripang, dan udang adalah 1 $\mathrm{mg} / \mathrm{Kg}$, sedangkan untuk buah dan sayuran adalah sebesar 0,2 mg/Kg. Berdasarkan data tersebut menunjukkan bahwa metode ini dapat menentukan kadar Cd untuk keamanan 
produk pangan yang diduga terkontaminasi $\mathrm{Cd}(\mathrm{II})$, karena mampu mendeteksi logam Cd(II) dari 0,1 hingga 1 ppm yang ditunjukkan dari Gambar 5.

Pembuatan kurva kalibrasi Cd(II) tersebut digunakan untuk mengetahui kandungan Cd(II) dalam sampel makanan. Sampel yang digunakan berupa ikan segar lele, mujer, tongkol dan daun kangkung.preparasi sampel dengan menggunakan destruksi basah dengan asam dan microwave. Hasil dari destruksi tersebut kemudian ditambahkan reagen pengkelat Alizarin Red $S$ dan dalam suasana asam sehingga terbentuk warna kuning pada kertas PAD yang ditunjukkan pada Gambar 6 a, b c dan d.
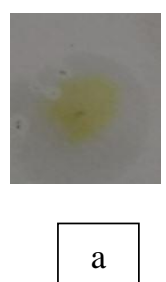
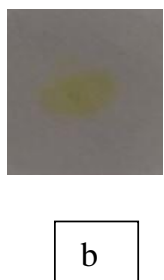
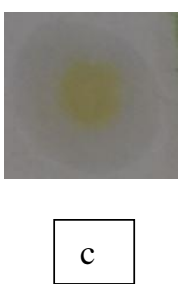
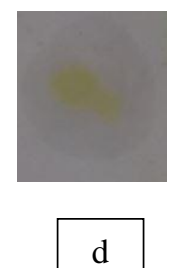

Gambar 6. Hasil PAD dengan Berbagai

Sampel (a) kangkung; (b) mujaer; (c) lele; (d) pindang tongkol.

Kemudian dilakukan analisis secara pencitraan digital dengan warna komplementer biru sehingga diperoleh absorbansi dari masing-masing sampel. Untuk mencari nilai konsentrasi dari masingmasing sampel dilakukan dengan cara memplotkan ke dalam persamaan regresi linearitas $\mathrm{Cd}(\mathrm{II})$ secara PAD yang diperoleh dari Gambar 3. Hasil masing-masing sampel makanan tersebut disajikan pada Tabel 3 .

Tabel 3. Konsentrasi masing-masing sampel makanan dengan metode PAD

\begin{tabular}{|l|l|l|l|l|}
\hline Sampel & Io & I & A & $\begin{array}{l}\text { Cd(II) } \\
\text { (ppm) }\end{array}$ \\
\hline $\begin{array}{l}\text { Kangkung } \\
(\mathrm{d})\end{array}$ & 255 & 116.858 & 0.339 & 0.139 \\
\hline Mujaer(c) & 255 & 112.205 & 0.357 & 0.210 \\
\hline Lele (b) & 255 & 104.143 & 0.389 & 0.341 \\
\hline $\begin{array}{l}\text { Pindang } \\
\text { Tongkol(a) }\end{array}$ & 255 & 100.137 & 0.406 & 0.409 \\
\hline
\end{tabular}

Mengacu pada Gambar 6 terlihat bahwa warna kuning dari hasil PAD paling pekat adalah pindang tongkol, kemudian lele, mujaer dan yang paling pudar adalah sayuran kangkung. Hal ini sesuai dengan Tabel 3 yang menunjukkan bahwa pindang tongkol memiliki kandungan Cd(II) tertinggi dan sayuran kangkung yang paling rendah.

Pemilihan sampel makanan berupa jenis ikan dan sayuran karena jenis makan tersebut berpotensi dapat terpapar oleh logam Cd(II). Proses pencemaran berasal dari laut, kemampuan logam berat terakumulasi dalam biota laut seperti ikan. Pencemar lain yang berasal dari industri, kendaraan bermotor dimungkinkan dapat mencemari sayuran yang ditanam di pinggir jalan (Yusuf, et al., 2016).

Untuk perbandingan hasil konsentrasi $\mathrm{Cd}(\mathrm{II})$ pada berbagai sampel makanan dengan metode AAS (Atomic Absorption Spectrophotometer) dan PAD yang diusulkan ditunjukkkan pada Tabel 4.

Tabel 4. Kandungan $\mathrm{Cd}(\mathrm{II})(\mathrm{ppm} / \mu \mathrm{g} / \mathrm{g})$ pada masing-masing sampel makanan dengan metode PAD dan AAS.

\begin{tabular}{|l|c|c|}
\hline Sampel & PAD & AAS \\
\hline Kangkung & 0.139 & 0.07 \\
\hline Mujaer & 0.210 & 0.16 \\
\hline Lele & 0.341 & 0.30 \\
\hline $\begin{array}{l}\text { Pindang } \\
\text { Tongkol }\end{array}$ & 0.409 & 0.38 \\
\hline
\end{tabular}

Berdasarkan Tabel 4 menunjukkan nilai kandungan $\mathrm{Cd}$ (II) dalam sampel makanan dengan metode PAD berbasis kompleks Alizarin Red $S$ dengan analisis menggunakan pencitraan digital sedikit lebih besar dibandingkan dengan metode AAS. Hal ini dikarenakan reagen Alizarin Red $S$ juga dapat membentuk kompleks dengan logam lain. Dalam sampel makanan seperti ikan, dan daun kangkung mengandung vitamin, mineral dan juga logam. Hal tersebut berpotensi mengganggu pengukuran dengan teknik PAD.

Rismiarti (2018) menyebutkan teknik analisa PAD untuk deteksi kadmium dengan kompleks Alizarin Red $S$, pengukurannya selektif terhadap ion $\mathrm{Zn}$ (II) dan $\mathrm{Pb}$ (II), pada konsentrasi kedua ion logam tersebut 0,1 ppm 
dengan konsentrasi Cd(II) 0,3 ppm dan bersifat menganggu pengukuran pada konsentrasi $\mathrm{Zn}$ (II) dan $\mathrm{Pb}$ (II) masing-masing adalah 1; 10 dan 100 ppm karena terjadi kenaikan nilai absorbansi dibandingkan tanpa ion asing. Terjadinya kenaikan nilai absorbansi tersebut sebanding dengan peningkatan nilai konsentrasi.

Mengacu pada Tabel 4 menunjukkan bahwa kandungan $\mathrm{Cd}(\mathrm{II})$ dalam daun kangkung masih dalam batas aman karena tidak melebihi ambang batas SNI 7387:2009 sebesar 0,2 ppm. Sedangkan kandungan Cd(II) dalam sampel ikan mujaer, lele, pindang tongkol pada kedua metode PAD dan AAS melebihi ambang batas SNI 7387:2009 yaitu sebesar 0,1 ppm.

Logam berat yang telah masuk ke badan air dapat mencemari biota laut, seperti ikan-ikan kecil tanaman air. Selanjutnya ikan-ikan besar dalam laut dapat memangsa ikan berukuran kecil yang telah terpapar oleh logam berat, sehingga konsentrasi dalam daging ikan besar akan lebih tinggi dibandingkan pada daging ikan kecil. Hal tersebut mengakibatkan terjadinya proses bioakumulasi, yaitu logam berat akan terakumulasi sehingga terjadi peningkatan kadar logam berat dalam jaringan tubuh organisme air yang hidup. Kemudian melalui proses biotransformasi akan terjadi perpindahan dan peningkatan kadar logam berat pada tingkat pemangsaan yang lebih tinggi (Maddusa dan Asrifuddin, 2016).

Proses selanjutnya adalah manusia mengkonsumsi ikan yang telah terpapar logam berat tersebut dapat terkontaminasi oleh logam berat $\mathrm{Cd}(\mathrm{II})$. Dalam tubuh manusia, akumulasi logam Cd(II) dalam jangka waktu yang lama dapat menghambat kerja paru-paru, pertumbuhan lambat dan osteoporosis. Oleh karena itu, proses pencemaran $\mathrm{Cd}(\mathrm{II})$ dalam badan air, biota laut sangat berdampai pada rantai makanan. Akumulasi Cd(II) dalam ikan sebagian besar adalah dalam organ hati dan ginjal karena adanyaprotein 'metallothionin' yang dapat mengikat logam $\mathrm{Cd}(\mathrm{II})$ (Yumiarti et al., 1996).

\section{KESIMPULAN}

Metode PAD berbasis kompleks Alizarin Red $S$ dengan analisis menggunakan teknik pencitraan digital dapat digunakan untuk mendeteksi kandungan $\mathrm{Cd}$ (II) dalam senyawa. Hasil penelitian menunjukkan kandungan $\mathrm{Cd}(\mathrm{II})$ dengan metode yang disulkan dalam sampel makanan seperti daun kangkung, ikan segar mujaer, lele, dan pindang tongkol masing - masing secara berurutan adalah $0.139 ; 0.210 ; 0.3410 .409$ $\mathrm{mg} / \mathrm{g} \mathrm{Cd}$ (II).

\section{UCAPAN TERIMAKASIH}

Penulis mengucapkan terimakasih kepada Kementrian Riset dan Teknologi Pendidikan Tinggi (Kemenristekdikti) atas dukungan dana penelitian melalui Hibah Penelitian Dosen Pemula (PDP) TA. 2017.

\section{DAFTAR PUSTAKA}

Busa, L.S.A, S. Mohammadi, M. Maeki, A. Ishida, H. Tani dan M. Tokeshi. 2016. Advancesin Microfluidic Paper-Based Analytical Devices for Food Water Analysis, Micromachines, 7, 86.

Cesur, H, and B. Bati. 2002. Determination Of Cadmium By FAAS After SolidPhase Extraction Of Its 1-Benzylpiperazinedithiocarbamate Complex On Microcrystalline Naphthalene. Turk J Chem 26(29).

Chaiyo, S., W. Siangproh, A. Aplux, and O. Chailapakul. 2015. Highly Selective And Sensitive Paper-Based Colorimetric Sensor Using Thiosulfate Catalytic Etching Of Silver Nanoplates For Trace Determination Of Copper Ions. Analytica Chimica Acta, 866, 25:75-83.

Istarani, F., dan E. Pandebesie. 2014. Studi Dampak Arsen (As) Dan Kadmiuj (Cd) Terhadap Penurunan Kualitas Lingkungan. Jurnal Teknik Pomits 3(1).

Kohl, K.S. D.J. Landmark, and F.D. Stickle. 2006. Demonstration of Absorbance Using Digital Color Image Analysis and Colored Solutions. J.Chem.Educ, 83(4), 644.

Liana, D.D., B. Raguse, J.J. Gooding, and E. Chow. 2012. Recent Advances in Paper-Based Sensors. Sensors, 12, 11505-11526. 
Maddusa, S.S., dan A. Asrifuddin. 2016. Studi Kandungan Kadmium (Cd) Pada Biota, Sedimen Dan Air Pada Sungai Pangkajene Kecamatan Bungoro Kabupaten Pangkep. Jurnal Paradigma Sehat. 4(1), 70-78.

Marzo, A.M.L., J. Pons, D.A. Blake, and A. Merkoçi. 2013. All-Integrated and Highly Sensitive Paper Based Device with Sample Treatment Platform for $\mathrm{Cd} 2+$ Immunodetection in Drinking/Tap Waters. Anal. Chem, $85,3532-3538$.

Ong, K. 2014. Determination of Lead And Cadmium In Foods By Grap hite Furnace Atomic Absorption Spectroscopy, www.perkinelmer.com. USA.

Prayitno, 2007. Pemisahan Kadmium Dalam Limbah Cair Industri Percetakan Dengan Sistem Elektromagnetik Plating, Prosiding, Prosiding PPI - PDIPTN 2007, Pustek Akselerator vDan Proses Bahan - Batan.

Rawat. J.P., U. Nasaer, and S.M.A. Andrabi. 2012. Chelation Ion Chromatography On Alizarin Red S Loadied Srannic Silicate-Selective Separation Of $\mathrm{Cd}^{2+}$ And $\mathrm{Pb}^{2+}$ Frome Some Transition Metal Ions. Indian Journal of Chemical Technology, 19:71-74.

Rismiarti, Z., dan R. Indrawati. 2017. Karakterisasi Metode Paper Analytical Device Berbasis Pencitraan Digital Untuk Deteksi Kadmium. Chem. Prog.10( 2), 52-57.

Rismiarti, Z. 2018. Pengaruh Ion $\mathrm{Pb}$ (II) dan Zn(II) Pada Metode Paper Analytical Device-Cadmium(II) (PAD-Cd(II)) Berbasis Kompleks Alizarin Red S Dengan Analisis Menggunakan Pencitraan Digital. Prosiding Seminar Nasional Inovasi Dan Aplikasi Teknologi Di Industri (SENIATI) 2018.

Rusmawan, C. A., D. Onggo, dan I. Mulyani. 2011. Analisis Kolorimetri Kadar Besi(III) dalam Sampel Air Sumur Dengan Metoda Pencitraan Digital. Prosiding Simposium Nasional Inovasi Pembelajaran dan Sains, $1-6$.
Yusuf, M., K. Nurthjahja, dan R. Lubis, 2016, Analisis Kandungan Logam Pb, $\mathrm{Cu}, \mathrm{Cd}$, dan Zn Pada Sayuran Sawi, Kangkung dan Bayam, Di areal Pertanian dan Industri Desa Paya Rumput Titipapan Medan, BioLink, 3(1), 56-64.

Yumiarti, J., Mellawati, dan S. Suwirma. 1996. Akumulasi, Ditribusi, Dan Toksisitas Cd Terhadap Ikan Lele (Clarias batrachus) Dalam Air. Aplikasi Isotop dan Radiasi, 109-113. 